Научная статья

УДК 631.162:657.22:637

DOI: $10.17213 / 2075-2067-2021-5-98-105$

\title{
АНАЛИЗ ОШИБОК, ВОЗНИКАЮЩИХ ПРИ ФОРМИРОВАНИИ НАЧАЛЬНОЙ МАКСИМАЛЬНОЙ ЦЕНЫ ДОГОВОРА
}

\author{
Елена Ивановна Зацаринная ${ }^{1 \rrbracket}$, Альбина Николаевна Семенова ${ }^{2}$ \\ ${ }^{1,2}$ Российский экономический университет имени В. Плеханова, Москва, Россия \\ ${ }^{1}$ e29175z@yandex.ru ${ }^{\bowtie}$, ORCID: 0000-0002-9400-4285, AuthorID РИНЦ: 679493 \\ ${ }^{2}$ semenovaalbina@mail.ru, AuthorID РИНЦ: 432696
}

Аннотация. Целью исследования является проведение анализа основных ошибок, возникающих при формировании начальной максимальной ичены договора.

Методологическую базу исследования представляют общенаучные методы: анализ, обобщение, приемы систематизации и классификации.

Результаты исследования. Перечень основных норм, которые регламентируют формирование и обоснование начальной максимальной иены договора, отражены в законодательных актах, регулирующих закупочные процедуры. Заказчики, которые размещают заказы в рамках Федерального закона №223, обязаны указывать в извещении и тендерной документации сведения о начальной максимальной цене договора. Порядок её определения организачии разрабатывают самостоятельно и закладывают в Положение о закупках, но необходимо помнить, что она должна быть экономически выгодной как для поставщика, так и для заказчика. На основе проведенного анализа порядка расчета и методов обоснования начальной максимальной изены договора в организациях были выявлены основные ошибки, возникающие при формировании начальной максимальной иены договора.

Перспективу исследования составляет вывод о необходимости вовремя выявлять, идентифицировать и исправлять все ошибки, совершаемые при расчете начальной максимальной иены договора.

Ключевые слова: начальная (максимальная) ичена договора (НМЦД), обоснование, частная проблема, метод расчета, заказчик

Для цитирования: Зачаринная Е. И., Семенова А. Н. Анализ ошибок, возникающих при формировании начальной максимальной цены договора // Вестник Южно-Российского государственного технического университета. Серия: Социально-экономические науки. 2021. T. 14, № 5. C. 98-105. http://dx.doi.org/10.17213/2075-2067-2021-5-98-105.

Original article

\section{ANALYSIS OF ERRORS ARISING IN THE FORMATION OF THE INITIAL MAXIMUM PRICE OF THE CONTRACT}

\author{
Elena I. Zatsarinnaya ${ }^{1 \bowtie}$, Albina N. Semenova ${ }^{2}$
}

(C) Зацаринная Е. И., Семенова А. Н., 2021 
Вестник ЮРГТУ (НПИ). Серия: Социально-экономические науки. 2021 г. T. 14. № 5 Bulletin of the SRSTU (NPI). Series: Socio-Economic Sciences. 2021. Vol. 14. № 5

\title{
${ }^{1,2}$ Plekhanov Russian University of Economics, Moscow, Russia ${ }^{1}$ 229175z@yandex.ru ${ }^{\bowtie}$,ORCID: 0000-0002-9400-4285, AuthorID RSCI: 679493 ${ }^{2}$ semenovaalbina@mail.ru,AuthorID RSCI: 432696
}

\begin{abstract}
The purpose of the study is to analyze the main errors that arise when forming the initial maximum contract price.

The methodological basis of the research is represented by general scientific methods: analysis, generalization, methods of systematization and classification.

Research results. The list of the main norms that regulate the formation and justification of the initial maximum contract price is reflected in the legislative acts regulating procurement procedures. Customers who place orders under Federal Law №223 are required to indicate information about the initial maximum contract price in the notice and tender documents. The organization develops the procedure for determining it independently and puts it in the Procurement Regulations, but it must be remembered that it should be economically profitable for both the supplier and the customer. Based on the analysis of the calculation procedure and methods for justifying the initial maximum contract price in the organizations, the main errors that arise when forming the initial maximum contract price were identified.

The prospect of the study is the conclusion that it is necessary to timely identify, identify and correct all errors made when calculating the initial maximum price of the contract.

Keywords: the initial (maximum) price of the contract (IMPC), justification, private problem, calculation method, customer

For citation: Zatsarinnaya E.I., Semenova A.N. Analysis of errors arising in the formation of the initial maximum price of the contract // Bulletin of the South Russian State Technical University. Series: Socio-economic Sciences. 2021; 14(5): 98-105. (In Russ.). http://dx.doi. org/10.17213/2075-2067-2021-5-98-105.
\end{abstract}

Введение. В настоящее время контролирующие органы и ведомственные организации уделяют пристальное внимание проблеме формирования и обоснования начальной (максимальной) цены контракта (НМЦК), цены контракта, заключаемого с единственным поставщиком, при планировании и проведении закупок в соответствии с Федеральным законом №44-Ф3'

Заказчику необходимо определять и обосновывать НМЦК с учетом необходимости достижения целей обеспечения государственных и муниципальных заказов, а также не забывая про ответственность за достижение этих целей [7]. Случаи завышения или занижения НМЦК в сравнении с реальными рыночными ценами товаров, работ или услуг приводят к ситуациям, нарушающим и противоречащим целям Федерального закона №44-Ф3.
Следовательно, формирование закупочных цен играет ключевую роль в сфере закупок. Корректное ценообразование позволяет исключить нарушения по контракту, провести закупочную процедуру с положительным эффектом, как для поставщика, так и для заказчика, и по возможности избежать судебных споров между инициатором и участниками закупки [2].

Основная часть. Начальная (максимальная) цена контракта является одним основных факторов, определяющих эффективность проведения конкурентной закупочной процедуры [5]. Основополагающей и первоочередной задачей каждого заказчика должен быть правильный расчет и обоснование начальной цены контракта, методов ее определения.

1 Федеральный закон от 05.04.2013 №44-Ф3 «О контрактной системе в сфере закупок товаров, работ, услуг для обеспечения государственных и муниципальных нужд». 
На законодательном уровне порядок формирования НМЦК прописан в статье 22 Федерального закона №44-Ф3².

Федеральный закон №223-Ф3³ не устанавливает определенные правила формирования НМЦК, но содержит информацию, что сведения или формула НМЦК и максимальное значение контракта должны быть включены в извещение об осуществлении конкурентной закупочной процедуры [8].

Алгоритм определения и обоснования НМЦК содержит некую стандартную последовательность действий заказчика, представленную на рисунке 1.

Кроме порядка действий, необходимо также знать и уметь применять на практике основные правила и методы расчета НМЦК [4].
Часть 1 статьи 22 Федерального закона №44-Ф3 закрепляет методы расчета НМЦК, которые отражены на рисунке 24 .

Начальная максимальная цена договора (НМЦД) - это ключевое звено в документации коммерческих закупок, регулируется п. 5 ч. 9 статьи 4 №223-Ф3 [3]. Применение и методы определения НМЦД по 223-ФЗ аналогичны использованию и схемам расчёта НМЦК по 44-ФЗ.

После расчета НМЦД производится проверка достоверности такого расчета и обоснования НМЦД путем проведения финансовой экспертизы.

Анализируя основные ошибки, возникающие при формировании начальной максимальной цены договора, можно условно их разделить на две большие группы: общие
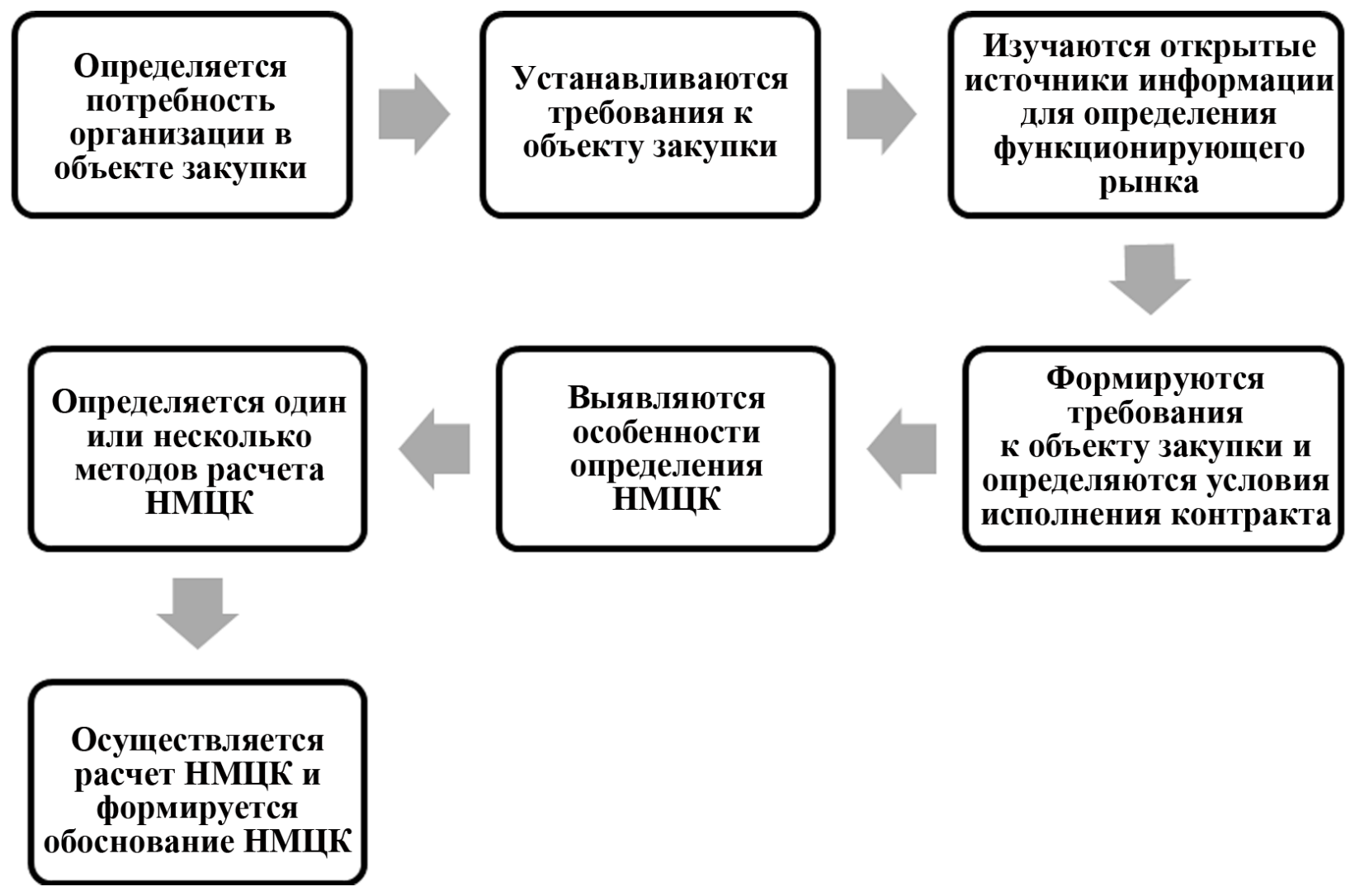

Рис. 1. Алгоритм действий при расчете и обосновании НМЦК

Fig. 1. Algorithm of actions when calculating and justifying the IMCP

2 Федеральный закон от 05.04.2013 №44-Ф3 «О контрактной системе в сфере закупок товаров, работ, услуг для обеспечения государственных и муниципальных нужд».

3 Федеральный закон от 18.07.2011 №223-Ф3 «О закупках товаров, работ, услуг отдельными видами юридических лиц».

4 Федеральный закон от 05.04.2013 №44-Ф3 «О контрактной системе в сфере закупок товаров, работ, услуг для обеспечения государственных и муниципальных нужд». 
и частные, относящиеся к выбранному методу расчета.

К общим, часто возникающим ошибкам, относятся:

- выбор некорректного метода расчета НМЦ лота;

- необоснованное использование только одного метода расчета НМЦД;

- арифметические ошибки в расчете;

- обоснование и приведение в расчете НМЦД меньшего количества позиций, чем было заявлено в закупочной процедуре;

- отсутствие приложения к обоснованию расчета НМЦД всех использованных в расчете источников ценовой информации или же вообще отсутствие обоснования расчета НМЦД;

- несоответствие величины НМЦД величине, указанной в закупочной документации, в SAP SRM при формировании закупочной процедуры и в других документах.

Перечисленные ошибки чаще всего напрямую зависят от закупщика, проводящего расчет НМЦ лота. К проявлению человеческого фактора можно отнести как арифметические ошибки и невнимательность при заполнении документов, так и выгрузку всех подтверждающих документов. Примером служит ситуация, когда сотрудником к обоснованию НМЦ лота приложено 50 спецификаций вместо 52 штук, используемых в расчете. Выбор корректного метода расчета напрямую зависит от знания ответственным специалистом Федерального закона №223-
Ф3 [1], Положения Компании о закупке ТРУ, Методических указаний компании о порядке расчета НМЦД и других локальных нормативных документов.

Далее представлены ошибки частные, возникающие при использовании различных методов расчета НМЦД.

В результате проверки использования ретроспективно-индексного метода были выявлены следующие ошибки:

- использование спецификаций за период поставки более одного года;

- некорректное индексирование НМЦД в зависимости от периода поставки;

- некорректное применение коэффициентов при пересчете валютных договоров в рубли для расчета НМЦД (доллары, евро);

- использование спецификаций, отличающихся по базису поставки, без применения корректирующих коэффициентов;

- неэффективное ведение реестра договоров и спецификаций, заключенных на основании прошедших закупок;

- неудобный функционал выгрузки оригиналов источников цен (договоров, дополнительных соглашений, спецификаций) из $1 \mathrm{C}$.

При применении метода сопоставления с ценами МТР-аналогов в целом допускаются такие же ошибки, как и при расчете ретроспективно-индексным методом. Однако отдельно можно выделить тот факт, что часто ответственным закупщиком допускается ошибка по некорректному подбору МТР-ана-

\section{Нормативный}

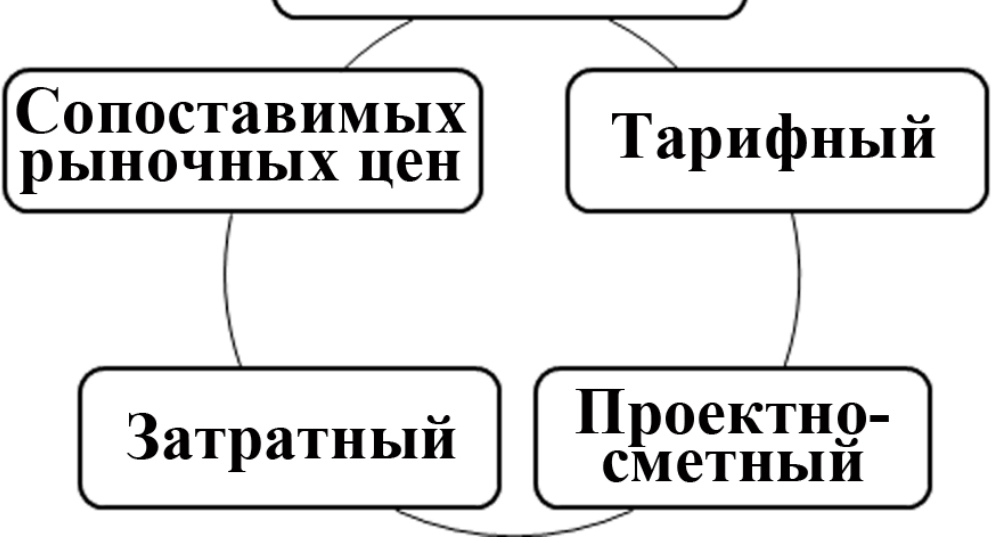

Рис. 2. Методы расчета НМЦК

Fig. 2. Methods for calculating IMCP 
лога. К примеру, МТР-аналогом может быть выбрана продукция, сильно отличающаяся по функциональным или техническим характеристикам. Следовательно, такой источник НМЦД не будет являться корректным и не должен быть принят в расчет.

Оценивая показатели расчета НМЦД с помощью централизованной информационной системы - справочника КСЦ, можно сделать следующие выводы об эффективности работы данного метода расчета:

- данные в справочнике могут подтягиваться из спецификаций со сроком поставки более одного года, использование таких данных не является корректным;

- цена по определенной номенклатуре не может использоваться для любых закупок, так как в справочнике не учитываются поправки в связи с отклонением параметров реальной закупки от условий предыдущих поставок.

Что касается метода сопоставимых рыночных цен, основными выявленными ошибками являются:

- направление запроса коммерческих предложений поставщикам, которые не осуществляют поставку идентичных или однородных ТРУ;

- отсутствие фиксирования исходных данных при использовании открытых источников информации для расчета НМЦ лота по мелкой закупке (скриншоты - снимки экрана или другие доступные методы фиксирования информации);

- неприменение коэффициентов и индексов для пересчета цен, полученных при применении метода анализа рынка, в том числе в зависимости от региона поставки;

- определение итоговой начальной максимальной цены, основанное исключительно на ценовых предложениях, предоставленных потенциальными поставщиками.

Дополнительной проблемой при расчете НМЦ лота методом анализа рынка становится отсутствие в системе единого реестра поставщиков с указанием поставляемой номенклатуры. Данная проблема особенно проявляется в случаях, когда закупщик получает в работу закупку по совершенно другой номенклатуре, но список рассылки по данной номенклатуре отсутствует [9].

При расчете НМЦД параметрическим методом закупщику довольно легко допус- тить ошибку, тем более, если ранее сотрудник не работал с данным методом расчета [6]. Так, может быть допущена ошибка с определением основного параметра МТР, на основании которого должен производиться расчет. В зависимости от номенклатуры это может быть мощность, производительность, вес, скорость МТР. Также может быть некорректно введена поправка на разницу технических параметров, комплектацию каких-либо товаров, срок поставки и условия заключения договора.

Выводы. Законодательство в сфере закупок товаров, работ и услуг содержит перечень норм, регламентирующих формирование и обоснование НМЦД. В нормативном регулировании закупочных процедур важное значение отводится и Федеральному закону №223-Ф3 [2], но его нормы не дают пояснений, к каким методам необходимо прибегать при осуществлении расчета НМЦД. Заказчику необходимо помнить, что обоснование расчета НМЦД выполняется с целью реализации предписаний антимонопольного законодательства и принципов закупочных процедур в отношении отдельных юридических лиц. В связи с этим возможные ошибки, совершаемые при расчете НМЦД, необходимо вовремя выявлять, идентифицировать и исправлять [10]. От этого зависит не только результат проводимой закупочной процедуры, но и предотвращение подобных ошибок в дальнейшем.

\section{Список источников}

1. Бакулина А.А., Карпова С.В. Проблемы ценообразования системы государственных закупок в условиях стимулирования конкуренции // Практический маркетинг. М.: Агентство «BCI Marketing», 2020. C. 3-9.

2. Зацаринная Е.И., Кленина А.И. Формирование закупочных цен на примере регионов: результаты мониторинга // В сборнике: Проблемы и перспективы развития промышленности России. Сборник материалов VIII Международной научно-практической конференции «Экономика промышленности в условиях ограничений». Под ред. А. В. Быстрова. М.: «РУСАЙНС», 2021. С. 129-135.

3. Карпова С.В. Обоснование начальной (максимальной) цены контракта в услови- 
ях электронных закупок [Электронный ресурс] // Проблемы современной экономики. СПб, 2019. С. 103-105. URL: http://elib.fa.ru/ art2019/bv851.pdf.

4. Коробейникова Л.С., Черников И.С. Особенности определения начальной (максимальной) цены контракта (договора) в анализе закупочной деятельности // Апрельские научные чтения имени профессора Л.Т. Гиляровской: материалы VIII Международной научно-практической конференции: в 2 частях. Воронеж: Воронежский государственный университет, 2019. С. 102-106.

5. Проданова Н.А., Георгадзе Н. Д., Сергеева А.Н. Референтные цены при определении НМЦК: попробуем разобраться // Бухучет в здравоохранении. М.: Издательский дом «Панорама», 2019. №7. С. 4-10.

6. Проданова Н.А.,, Филатова Е.И. Контроль исполнения контрактов для государственных и муниципальных нужд // Бизнес и дизайн ревю. М.: Институт бизнеса и дизайна, 2019. №3 (15). С. 3.

7. Pinchuk T., Kazantseva I., Shlepnev O. Model of formation of the price of the state construction contract in the conditions of innovative development of economy [Electronic resource] // MATEC Web of Conferences. 2018. Vol. 21208004. URL: https://www.matec-conferences.org/articles/matecconf/abs/2018/71/ matecconf icre $2018 \quad 08004 /$ matecconf icre2018_08004.html.

8. Сологуб А.Н., Новопашина Е. С. Формирование начальной (максимальной) цены контракта в рамках закона о контрактной системе // Современные проблемы развития экономики России и Китая: материалы Международной научно-практической конференции. Под общ. ред. О.А. Цепелева. Благовещенск: Амурский государственный университет, 2018. С. 117-119.

9. Толстобоков О.Н. Проблемы определения начальной цены контракта (договора) в системе государственных (муниципальных) закупок // Наука и бизнес: пути Развития. Тамбов: Фонд развития науки и культуры, 2020. С. 172-177.

10. Fedotov D.A. Improvement of the mechanism of rationing the initial contract price in the field of public procurement on the example of econometrics modelling of the price of laptop // Research Result. Economic Research. Belgorod:
Belgorod State National Research University, 2018. Vol. 4. №4. Pp. 53-65.

\section{References}

1. Bakulina A.A., Karpova S. V. Problemy cenoobrazovanija sistemy gosudarstvennyh zakupok v uslovijah stimulirovanija konkurencii [Problems of pricing of the public procurement system in terms of promoting competition]. Prakticheskij marketing [Practical marketing]. Moscow: Agentstvo «BCI Marketing», 2020. Pp. 3-9. (In Russ.).

2. Zacarinnaja E. I., Klenina A.I. Formirovanie zakupochnyh cen na primere regionov: rezul'taty monitoringa [The formation of the purchase price on the example of regions: the results of the monitoring]. V sbornike: Problemy i perspektivy razvitija promyshlennosti Rossii. Sbornik materialov VIII Mezhdunarodnoj nauchno-prakticheskoj konferencii «Jekonomika promyshlennosti v uslovijah ogranichenij». Pod red. A. V. Bystrova [In the collection: Problems and prospects of development of Russian industry. Collection of materials of the VIII International Scientific and Practical Conference «Industrial Economics under restrictions». In A. V. Bystrov (eds.)]. Moscow: «RUSAJNS», 2021. S. 129-135. (In Russ.).

3. Karpova S. V. Obosnovanie nachal'noj (maksimal'noj) ceny kontrakta $\mathrm{v}$ uslovijah jelektronnyh zakupok [Justification of the initial (maximum) contract price in terms of electronic procurement] [Jelektronnyj resurs]. Problemy sovremennoj jekonomiki [Problems of modern economics]. Saint Petersburg, 2019. Pp. 103105. URL: http://elib.fa.ru/art2019/bv851.pdf. (In Russ.).

4. Korobejnikova L. S., Chernikov I. S. Osobennosti opredelenija nachal'noj (maksimal'noj) ceny kontrakta (dogovora) v analize zakupochnoj dejatel'nosti [Features of determining the initial (maximum) price of a contract (contract) in the analysis of procurement activities]. Aprel'skie nauchnye chtenija imeni professora L.T. Giljarovskoj: materialy VIII Mezhdunarodnoj nauchno-prakticheskoj konferencii: v 2 chastjah [April scientific readings named after Professor L. T. Gilyarovskaya: materials of the VIII International Scientific and Practical Conference: in 2 parts]. Voronezh: Voronezhskij gosudarstvennyj universitet, 2019. Pp. 102-106. (In Russ.). 
5. Prodanova N.A., Georgadze N.D., Sergeeva A.N. Referentnye ceny pri opredelenii NMCK: poprobuem razobrat'sja [Reference prices when determining the MSPC: try to understand]. Buhuchet $v$ zdravoohranenii [Accounting in health care]. Moscow: Izdatel'skij dom «Panorama», 2019; 7: 4-10. (In Russ.).

6. Prodanova N.A., Filatova E. I. Kontrol' ispolnenija kontraktov dlja gosudarstvennyh i municipal'nyh nuzhd [Monitoring the execution of contracts for state and municipal needs]. Biznes $i$ dizajn revju [Business and design review]. Moscow: Institut biznesa i dizajna, 2019; 3 (15): 3 . (In Russ.).

7. Pinchuk T., Kazantseva I., Shlepnev O. Model of formation of the price of the state construction contract in the conditions of innovative development of economy [Electronic resource] // MATEC Web of Conferences. 2018. Vol. 21208004. URL: https://www.matec-conferences.org/articles/matecconf/abs/2018/71/ matecconf_icre2018_08004/matecconf_ icre2018_08004.html.

8. Sologub A. N., Novopashina E. S. Formirovanie nachal'noj (maksimal'noj) ceny kontrakta $\mathrm{v}$ ramkah zakona o kontraktnoj sisteme [ormation of the initial (maximum) contract price within the framework of the law on the contract system]. Sovremennye problemy razvitija jekonomiki Rossii i Kitaja: materialy Mezhdunarodnoj nauchno-prakticheskoj konferencii. Pod obshh. red. O.A. Cepeleva [Modern problems of economic development of Russia and China: materials of the International scientific and practical Conference. In O.A. Tsepelev (eds.)]. Blagoveshhensk: Amurskij gosudarstvennyj universitet, 2018. Pp117-119. (In Russ.).

9. Tolstobokov O.N. Problemy opredelenija nachal'noj ceny kontrakta (dogovora) v sisteme gosudarstvennyh (municipal'nyh) zakupok [Problems of determining the initial price of a contract (contract) in the system of state (municipal) procurement]. Nauka i biznes: puti Razvitija [Science and Business: ways of Development]. Tambov: Fond razvitija nauki i kul'tury, 2020. Pp. 172-17. (In Russ.).

10. Fedotov D.A. Improvement of the mechanism of rationing the initial contract price in the field of public procurement on the example of econometrics modelling of the price of laptop // Research Result. Economic Research. Belgorod: Belgorod State National Research University, 2018. Vol. 4. №4. Pp. 53-65.

Статья поступила в редакцию 04.09.2021; одобрена после рецензирования 21.09.2021; принята к публикаиии 26.09.2021.

The article was submitted on 04.09.2021; approved after reviewing on 21.09.2021; accepted for publication on 26.09.2021.

\section{ИНФОРМАЦИЯ ОБ АВТОРАХ}

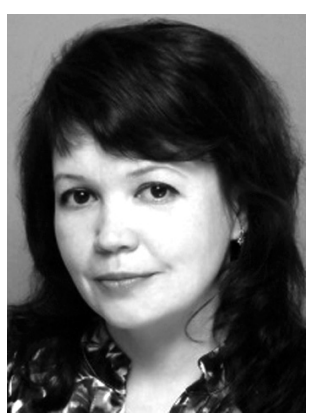

Зацаринная Елена Ивановна - кандидат экономических наук, доцент базовой кафедры «Финансовый контроль, анализ и аудит» Главного контрольного управления города Москвы Российского экономического университета имени Г. В. Плеханова.

Россия, г. Москва, Стремянный пер., 36

Elena I. Zatsarinnaya - Candidate of Economic Sciences, Associate Professor of the Base Department of Financial Control, Analysis and Audit, Main Control Department of Moscow, Plekhanov Russian University of Economics.

36 Stremyanny av., Moscow, Russia 


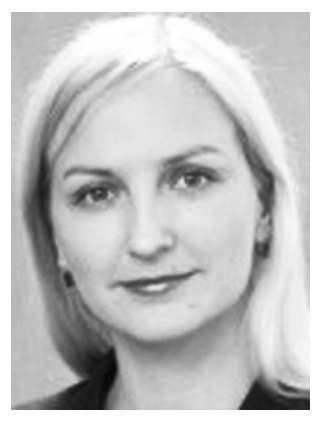

Семенова Альбина Николаевна - кандидат экономических наук, доцент базовой кафедры «Финансовый контроль, анализ и аудит» Главного контрольного управления города Москвы Российского экономического университета имени Г.В. Плеханова.

Россия, г. Москва, Стремянный пер., 36

Albina N. Semenova - Candidate of Economic Sciences, Associate Professor of the Base Department of Financial Control, Analysis and Audit, Main Control Department of Moscow, Plekhanov Russian University of Economics.

36 Stremyanny av., Moscow, Russia

\section{Вклад авторов:}

Зацаринная Е. И. - научное руководство; концепция исследования; развитие методологии; написание исходного текста; итоговые выводы.

Семенова А. Н. - доработка текста; итоговые выводы.

Contribution of the authors:

Zatsarinnaya E. I. - scientific leadership; research concept; development of methodology; writing the source text; final conclusions.

Semenova A. N. - revision of the text; final conclusions. 